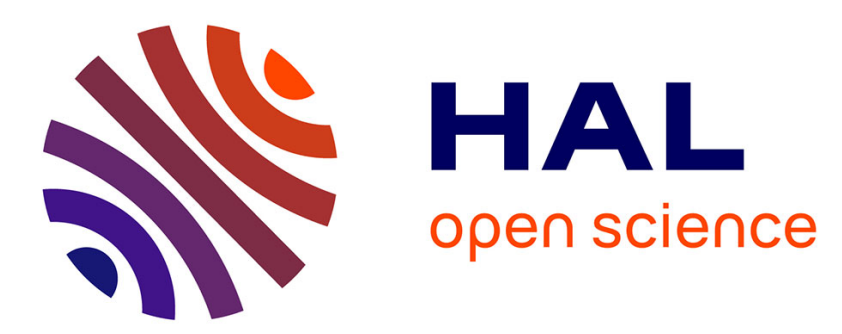

\title{
13C-NMR characterization of formaldehyde bonds in model mixtures and proteins containing lysine
}

\author{
D. Tome, N. Naulet, A. Kozlowski
}

\section{To cite this version:}

D. Tome, N. Naulet, A. Kozlowski. 13C-NMR characterization of formaldehyde bonds in model mixtures and proteins containing lysine. International Journal of Peptide and Protein Research, 1985, 25, pp.258-266. hal-02722002

\section{HAL Id: hal-02722002 \\ https://hal.inrae.fr/hal-02722002}

Submitted on 1 Jun 2020

HAL is a multi-disciplinary open access archive for the deposit and dissemination of scientific research documents, whether they are published or not. The documents may come from teaching and research institutions in France or abroad, or from public or private research centers.
L'archive ouverte pluridisciplinaire HAL, est destinée au dépôt et à la diffusion de documents scientifiques de niveau recherche, publiés ou non, émanant des établissements d'enseignement et de recherche français ou étrangers, des laboratoires publics ou privés. 


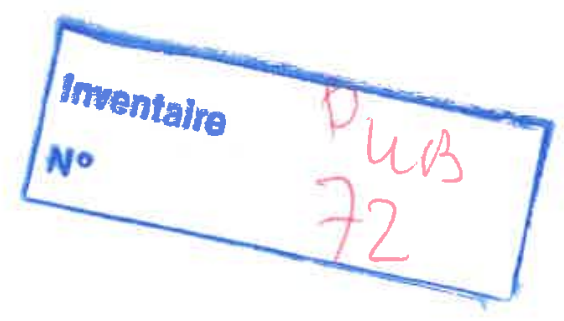




\title{
${ }^{13} \mathrm{C}-\mathrm{n} . \mathrm{m} . r$. characterization of formaldehyde bonds in model mixtures and proteins containing lysine
}

\author{
D. TOME, ${ }^{*}$ N. NAULET** and A, KOZLOWSKI* \\ *National Institute for Agricultural Research - Laboratory of Animal Feed Technology; \\ **University of Nantes - Organic Chemistry, ERA C.N.R.S. 315, Nantes, France
}

Received 12 April, accepted for publication 3 July 1984

\begin{abstract}
Reactions involving formaldehyde, lysine and another amino acid (tyrosine, arginine, asparagine, glutamine or cysteine) were studied by ${ }^{13} \mathrm{C}$-n.m.r. analysis. The products of the crosslinking between lysine and tyrosine were found to be acid-resistant and were isolated using ion exchange chromatography. With the other selected amino acids, the crosslinked products with lysine are acid-labile and could not be isolated; however, n.m.r. allows the determination of their structure. In addition, the formation of methyllysine and of formyllsine have been observed. The ${ }^{13} \mathrm{C}-\mathrm{n}$.m.r. chemical shifts of the formaldehyde derived hydroxymethyl, methylene, methyl and formyl carbons with the amino acids side chains help in the interpretation of ${ }^{13} \mathrm{C}$-enriched formaldehyde treated protein ${ }^{13}$ C-n.m.r. spectra. With BSA, we have observed the formation of hydroxymethyllysine, hydroxymethylhistidine, hydroxymethyl-asparagine or -glutamine, methyllysine, and a crosslink between lysine and arginine. These results show the great importance of lysine in the treatment of protein with formaldehyde. Use of ${ }^{13} \mathrm{C}-\mathrm{n}$.m.r. is considered highly suitable for obtaining more knowledge about formaldehyde binding to peptides and proteins.
\end{abstract}

Key words: amino acids; carbon 13 n.m.r.; formaldehyde; lysine; protein

Formaldehyde treatment of proteins, which is of importance in a number of procedures (1-4), can affect different chemical groups and particularly the $\epsilon$-amino group of lysine $(5,6)$. It is known that this latter group reacts with formaldehyde, resulting in $N$-hydroxymethyl (7-9), $N$-methyl (8), $N$-formyl $(10,11)$. The $N$-hydroxymethyl may then react on other nucleophilic sites, leading to the formation of methylene bridges; the amino acids involved have been tentatively identified as arginine $(12,13)$, tyrosine, histidine or tryptophan $(4,14)$, asparagine or glutamine $(12,15)$ and cysteine (16).

The above scheme can explain most of the modifications produced in peptides and proteins by formaldehyde treatment, but the mechanism by which they proceed has not yet been definitively established. The main drawbacks hindering identification of the reaction products are binding reversibility and low concentration. These difficulties can be overcome by use of ${ }^{13} \mathrm{C}$-enriched formaldehyde and ${ }^{13} \mathrm{C}$-n.m.r. spectroscopy (17). However, before obtaining a single step ${ }^{13} \mathrm{C}-n . m . r$.identification of the ${ }^{13} \mathrm{C}$-formaldehyde proteins bonds, we need to know the ${ }^{13} \mathrm{C}$-chemical shifts of the formaldehyde derived hydroxymethyl, methylene, methyl or formyl carbons of the different reactive groups suspected to be 
involved in the reaction. Some knowledge has already been obtained using model compounds $(13,18,19)$ and amino acids $(7,8,16,17)$.

This paper describes ${ }^{13} \mathrm{C}-n . m . r$. characterization of the bonds of formaldehyde or ${ }^{13} \mathrm{C}$ formaldehyde in model systems containing lysine or protected lysine in the presence of various protected amino acids. The obtained results allow interpretation, at least to some extent, of the ${ }^{13} \mathrm{C}$-n.m.r. spectra of ${ }^{13} \mathrm{C}$ formaldehyde treated proteins.

\section{EXPERIMENTAL PROCEDURES}

Amino acids and $N^{\alpha}$ acetyl amino acids (protected amino acids) were obtained from Sigma and used without further purification. Bovine serum albumin (BSA) (Sigma) was extracted with hexane prior to use. A 10-M solution of formaldehyde was prepared by depolymerisation of pure paraformaldehyde (Merck) in distilled water at $85^{\circ}$. A 6.5-M solution of ${ }^{13} \mathrm{C}$-formaldehyde ( $91 \%$ enriched) was obtained from Prochem.

Different model systems were designed in which either lysine and one protected amino acid (e.g. lysine and $N^{\alpha}$ acetylglutamine), or two protected amino acids (e g. $N^{\alpha}$ acetyllysine and $N$ acetyltyrosine) were allowed to react either with formaldehyde or with ${ }^{13} \mathrm{C}$-formaldehyde. The experiments were carried out in aqueous phase using different $\mathrm{pH}$, time and temperature conditions. The amino acid concentration was kept in the $0.1-0.5 \mathrm{M}$ range and the molar ratio of the added formaldehyde or ${ }^{13} \mathrm{C}$-formaldehyde to amino acids was fixed at $1-4$. pH adjustments were made with concentrated $\mathrm{HCl}$ or $\mathrm{NaOH}$. "Acid-labile" formaldehyde $(\mathrm{Fh})$ was steam-distilled off after addition of $o$-phosphoric acid $(0.5 \mathrm{ml}$ for $3 \mathrm{ml}$ of solution).

The compounds $\mathrm{A} 1$ and $\mathrm{A} 2$ (Table 1) were prepared and isolated as follows: protected lysine $(0.5 \mathrm{M})$ and protected tyrosine $(0.5 \mathrm{M})$ were mixed with formaldehyde $(0.5 \mathrm{M})$ or ${ }^{13} \mathrm{C}$-formaldehyde $(0.5 \mathrm{M})$ and allowed to stand at $\mathrm{pH} 7.5$ and $37^{\circ}$ for 1 week. Acid-labile formaldehyde was first eliminated, then deacetylation of amino groups was performed by hydrolysis in $6 \mathrm{M}$ hydrochloric acid for $24 \mathrm{~h}$ at $110^{\circ}$. The hydrolysate was then concen- trated under reduced pressure at $40^{\circ}$ and fractionated by ion exchange chromatography on a column $(60 \times 1.6 \mathrm{~cm})$ of Dowex $50 \mathrm{X} 4$ in pyridine acetate buffer $0.3 \mathrm{M}, \mathrm{pH} 4.7$. The column was regenerated by a pyridine acetate buffer $2.23 \mathrm{M}, \mathrm{pH}$ 5.4. The detection was carried out on an aliquot of the individual fractions by absorbance measurement at $560 \mathrm{~nm}$ after reaction with ninhydrin. The isolated compounds were concentrated under reduced pressure at $40^{\circ}$ in order to get rid of the pyridine acetate, and redissolved in water.

BSA was used at a concentration of $100 \mathrm{~g} / 1$ in sodium phosphate buffer $0.1 \mathrm{M}, \mathrm{pH} 7.5$, or in sodium acetate buffer $0.2 \mathrm{M}, \mathrm{pH}$ 4.5. The protein was treated with $0.33 \mathrm{M}{ }^{13} \mathrm{C}$-formaldehyde. Free ${ }^{13} \mathrm{C}$-formaldehyde was eliminated by means of dialysis against phosphate buffer.

${ }^{13}$ C-n.m.r. spectra were recorded in the pulsed Fourier Transform mode on a Bruker WH 90 spectrometer operating at $22.635 \mathrm{MHz}$, in $10 \mathrm{~mm}$ tubes. The field-frequency lock was provided by deuterated benzene (C6D6) put into a coaxial tube, and ${ }^{13} \mathrm{C}$ chemical shifts measured with respect to the central peak of C6D6 and calculated from TMS according to the relation: $\delta{ }^{13} \mathrm{C}(\mathrm{C} 6 \mathrm{D} 6)=\delta{ }^{13} \mathrm{C}(\mathrm{TMS})+$ 127 p.p.m. Typical running conditions were: $6000 \mathrm{~Hz}$ bandwidth, acquisition time $0.679 \mathrm{~s}$, $30^{\circ}$ flip angle without pulse delay, quadrature detection, broad band noise decoupling. Conditions for quantitative measurement were: $90^{\circ}$ flip angle; pulse delay $200 \mathrm{~s}$, broad band noise decoupling only during acquisition. Resonance lines were assigned by comparing experimental data with those previously reported in the literature. The use of resonance decoupling and of the APT pulses sequence (Attached Proton Test) helped in this assignment.

The nomenclature used is that of the IUPAC-IUB Commission on Biochemical Nomenclature [European J. Biochem. (1975) 53, 1-14].

\section{RESULTS AND INTERPRETATION}

In a preliminary study, mixtures of two protected amino acids with a reactive side chain (7) were allowed to react in the presence of 
D. Tome et al.
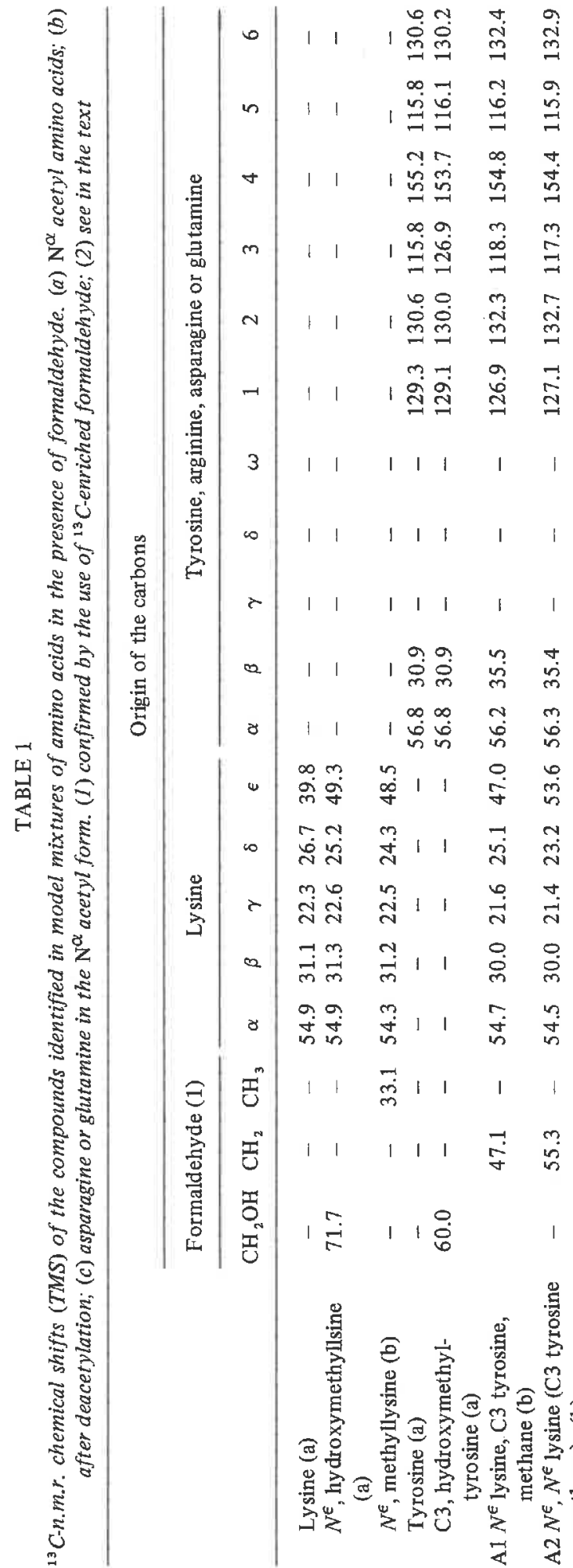

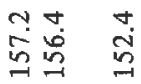

$\vec{z} \bar{z}$

宾守 学

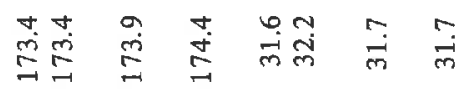

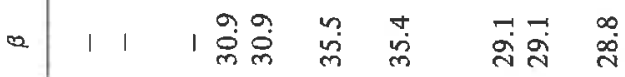

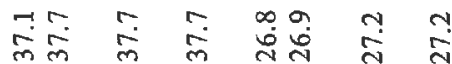

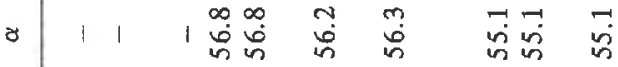

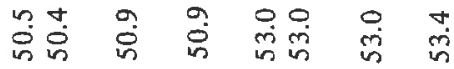

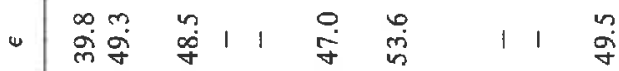

文

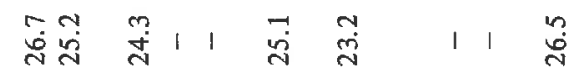

चु

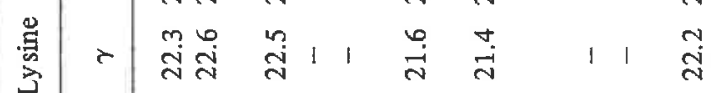

जे बे 11 ते

$\infty$ 莎

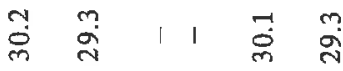

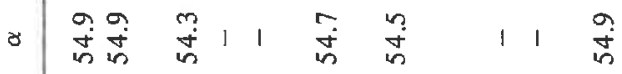

if

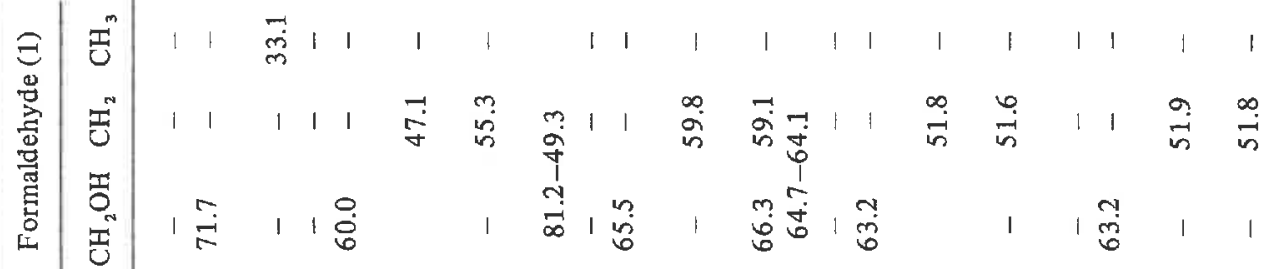

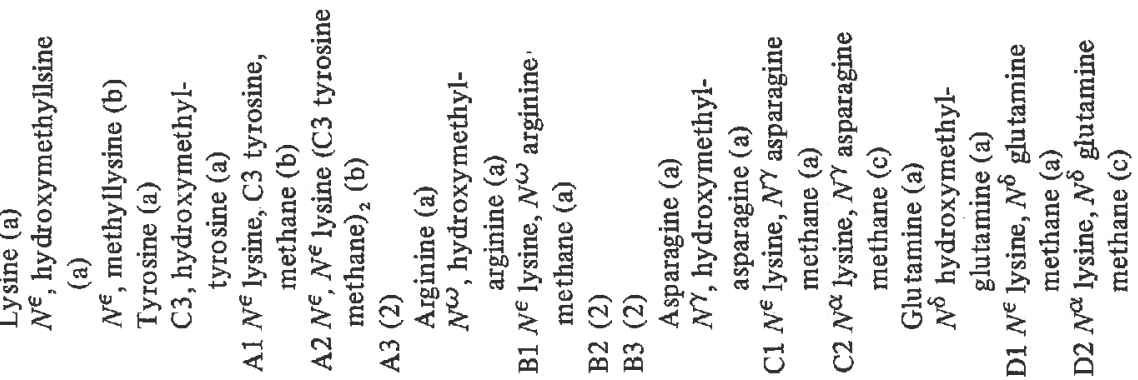


${ }^{13} \mathrm{C}$-formaldehyde bonds

formaldehyde. In most cases, only the reaction products of each side chain with formaldehyde were traced on the ${ }^{13}$ C-n.m.r. spectra $(7-9)$. In several cases, however, new reactions were observed, four of which, resulting in the formation of methylene bridges between cysteine and respectively lysine, arginine, asparagine and glutamine, have already been described in a previous paper (16). Other reactions, considered in this work, result in the formation of methylene bridges between lysine and tyrosine, arginine, asparagine or glutamine (Table 1). These reactions which involve lysine seem also predominant when BSA is treated with ${ }^{13} \mathrm{C}$ formaldehyde.

\section{Reactions between lysine, tyrosine and formaldehyde}

In acidic medium, protected tyrosine does not react with formaldehyde even if protected lysine is added. However, at pH higher than 6, the phenol ring becomes much more reactive.

In a system containing protected tyrosine and formaldehyde left at $\mathrm{pH} 7.5$ and $37^{\circ}$ for several days, a hydroxymethyl derivative is formed by addition of formaldehyde on the carbon 3 of the ring. This derivative is acid. labile and lost through formaldehyde steamdistillation. The reaction is never completed and not very favoured. If, under the same experimental conditions, protected lysine is added to the mixture in an equimolar ratio, different products are formed. Three of them are acid-resistant and have been isolated using ion exchange chromatography following deacetylation (Fig. 1); they have been identified by $n$ m.r. as methyllysine and products $A 1$ and A2. ${ }^{13}$ C-n.m.r. spectra carried out under quantitative conditions gave evidence of a ratio of $1: 1$ between lysine and tyrosine in $\mathrm{A} 1$ and $1: 2$ in A2. A third product A3 is characterized by two peaks at 81.6 and 49.5 p.p.m., deriving from formaldehyde. These two peaks always show the same intensity and they increase in intensity with an excess of formaldehyde; these products do not withstand the acid-labile formaldehyde elimination step and disappear with a subsequent increase of the peak at 47.3 p.p.m. (A1). Therefore, it was assumed that product $\mathrm{A} 3$ could result from a cyclisation in Al through a methylene bridge between the

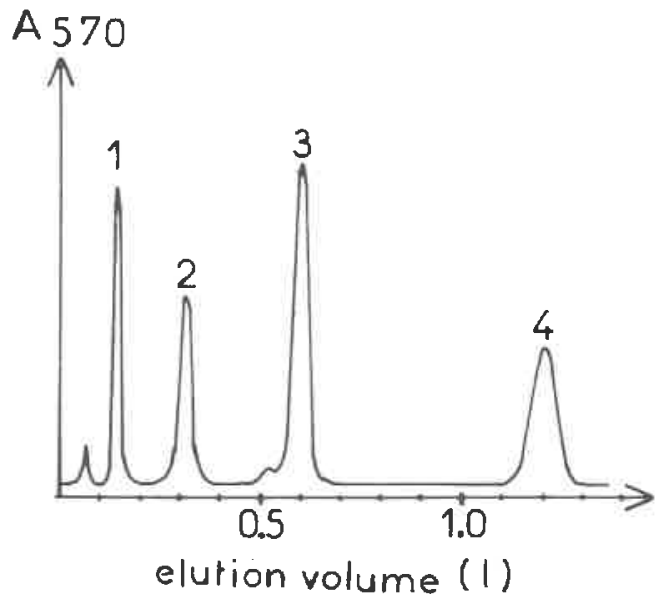

FIGURE 1

Elution profile from Dowex 50X4 ion exchange chromatography of the reaction products between protected lysine, protected tyrosine and formaldehyde (after deacetylation). The mixture ( $1 \mathrm{ml}$ ) was applied to the column $(60 \times 1.6 \mathrm{~cm})$ and the fractions were eluted with pyridine acetate $0.3 \mathrm{M}$-. pH 4.7 at a flow rate of $60 \mathrm{ml} / \mathrm{min} .{ }^{13} \mathrm{C}-\mathrm{n} . \mathrm{m}_{0}$. . analysis of each peak: 1-tyrosine; 2-lysine + methylly sine; 3 product A1;4-product A2

nitrogen of lysine side chain and the oxygen of the phenol ring of tyrosine.

After 5 days at $\mathrm{pH} 7.5$ and $37^{\circ}$, the solution still contains free formaldehyde and approximately $70 \%$ unreacted amino acids, $13 \%$ $\mathrm{A} 1,7 \% \mathrm{~A} 2,7 \% \mathrm{~A} 3$ and $3 \%$ methyllysine.

When an excess of formaldehyde and lysine is used, A2 decreases and A1, A3 and methyllysine increase. In addition, it was shown, with the help of ${ }^{13} \mathrm{C}$-formaldehyde, that dimethyllysine, with the methyl carbons at 42.8 p.p.m., and formyl lysine, characterized by the formyl carbons at 164.8 p.p.m., were built up. These latter products are found at low concentrations.

\section{Reaction between lysine, arginine and formaldehyde}

Protected arginine reacts with formaldehyde yielding an hydroxymethyl derivative on the guanidyl function, characterized by the ${ }^{13} \mathrm{C}$. n.m.r. peak of the hydroxymethyl carbon at 65.2 p.p.m. This derivative is the only one which is produced in a large range of $\mathrm{pH}$ and 


\section{Tome et al.}

represents nearly $35 \%$ of arginine when reagents are initially mixed in an equimolar ratio.

The reactions between protected lysine, protected arginine and formaldehyde are $\mathrm{pH}$

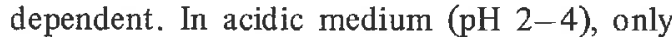
the hydroxymethyl derivative of each side chain can be traced on the ${ }^{13} \mathrm{C}$-n.m.r. spectra (hydroxymethyl carbons at 71.3 and 65.2p.p.m.); when the $\mathrm{pH}$ is higher than 4 , three new products $\mathrm{B} 1, \mathrm{~B} 2$ and $\mathrm{B} 3$ can be detected after several hours at room temperature.

The crosslinked product B1, which shows a methylene bridge between the side chain of lysine and arginine at 59.9 p.p.m., is always found in the largest amount. Its concentration increases when $\mathrm{pH}$ is increased with a concomitant disappearance of hydroxymethyllysine.

Product B2 is characterized by two methylene carbons deriving from formaldehyde at 66.3 and 59.1 p.p.m. These peaks are always of the same intensity and make up less than 5\% of the mixture. In light of the recorded chemical shifts, B2 can be considered a compound resulting from an hydroxymethylation of the free nitrogen of the guanidyl function of B1.

The product B3 is characterized by two methylene carbons at 64.2 and 64.8 p.p.m. deriving from formaldehyde. These peaks are always of the same intensity and make up about $3 \%$ of the products. They have not yet been identified and several hypotheses can be put forth. The most likely, if we consider their chemical shifts, is the formation of a dimethylene ether bridge between the side chains of lysine and arginine.

All these derivatives are acid labile and break up during the steam-distillation step. Therefore, we did not succeed in isolating them; however, if the reacting medium is acidified at room temperature, just after the derivative formation, B1 can still be found in the mixture. This gives some evidence of a relative stability of the methylene bridge.

After reaction of protected lysine, protected arginine and formaldehyde in an equimolar ratio at $\mathrm{pH} 7.5$ and $37^{\circ}$ for 1 day, it was found that formaldehyde had been entirely consumed and the mixture was approximately made up of $15 \%$ unreacted amino acids, $15 \%$ hydroxymethyl arginine, 60\% B1, 10\% B2 and $\mathrm{B} 3$.

\section{Reactions between lysine, asparagine or glutamine and formaldehyde}

The amide groups of protected asparagine and glutamine slowly react with formaldehyde to yield the hydroxymethyl derivatives (7).

In the presence of protected lysine, after several days at room temperature and in acidic medium only, the product of the cross-linking by a methylene bridge between the amide group of asparagine or glutamine and the $\epsilon$-amino group of lysine (products C1 and D1) can be traced on the ${ }^{13} \mathrm{C}$-n.m.r. spectra. The methylene signal is at 51.8 p.p.m. If protected lysine is replaced by lysine, a secondary reaction is also observed on the $\alpha$-amino group with the methylene bridge at 51.6 p.p.m. (C2 and D2). These amide-formald ehyde-amine condensation products are unstable and easily decompose when $\mathrm{pH}$ is higher than 5 ; therefore they cannot be isolated.

The proportions of the reaction products when the equilibrium is reached are the same for both amino acids. After reaction of an equimolar mixture of the three reagents at $\mathrm{pH} 2.5$ and $37^{\circ}$ for several days, only $20 \%$ of the formaldehyde has been used and the solution contains $75 \%$ unreacted amino acids, $5 \%$ hydroxymethyl-asparagine or -glutamine, $5 \%$ hydroxymethyllysine and $10 \%$ of the crosslinked products (C1 or D1).

\section{Reactions between ${ }^{13} \mathrm{C}$-formaldehyde and BSA}

Typical ${ }^{13} \mathrm{C}$-n.m.r. spectra obtained from BSA treated with ${ }^{13} \mathrm{C}$-enriched formaldehyde, either in acid ( $\mathrm{pH} 4.5)$ or neutral ( $\mathrm{pH} \mathrm{7.5)} \mathrm{solution,}$ are shown in Fig. 2.

The intensified resonances occur in a frequency range $30-80$ p.p.m. which is the region of the hydroxymethyl, methylene and methyl carbons resulting from the reaction of formaldehyde with amino acids side chains. The intensified resonances are not completely resolved because of an important line broadening. Moreover, due to the very low concentration on each bond, a long accumulation time is needed in order to obtain spectra. Denaturation of the modified protein would probably increase the resolution; however, all the attempts carried out either by thermal treatment or by adding chemical agents, resulted in precipitation of the protein. Despite these difficulties, five intensified peaks for which it is possible to 
postulate some structure are subsequently designated a, b, c, d, e.

Both in acidic and neutral medium, the first peak appears after some hours at 71.8 p.p.m. (a), which is the chemical shift of hydroxymethyllysine and hydroxymethylhistidine (7). In neutral medium only, another $N$-hydroxymethyl is formed at 70.2 p.p.m. (b) near the value of a $N$-terminal hydroxymethyl (8). These bonds decrease as the reaction goes on and disappear when ${ }^{13} \mathrm{C}$-formaldehyde is eliminated by dialysis. The reversibility of these linkages is in accordance with the properties of the $N$-hydroxymethyls.

Within a few days, a broad band appears between 50 and 70 p.p.m. In acidic medium its formation is accompanied by a gelification of the solution, preventing any obtention of resolved spectra, and the only additional identified peak is at 63.1 p.p.m. (c), which is exactly the chemical shift of the amide hydroxymethyl on asparagine or glutamine. In neutral medium, the products remain soluble; in that case, in addition to the aforementioned amide hydroxymethyl at 63.1 p.p.m. (c), there is another peak at 60.2 p.p.m. (d) very near the chemical shift of a lysine-arginine crosslink (59.9 p.p.m.) or of a tyrosine hydroxymethyl (60 p.p.m.). A well resolved peak appears, after several days, in neutral medium, at 33.1 p.p.m. (e); considering this chemical shift, it may be assumed that the compound is the $N$-methyllysine. The peaks $c$, d, e build up progressively during the reaction and are not affected when ${ }^{13} \mathrm{C}$-formaldehyde is eliminated by dialysis.

$8070 \quad \begin{gathered}60 \\ \text {-Ppm - }\end{gathered}$
-

\section{FIGURE 2}

90-MHz ${ }^{13} \mathrm{C}$-n.m.r. spectra of ${ }^{13} \mathrm{C}$-formaldehyde treated BSA at $37^{\circ} 1-\mathrm{pH} 4.5,10 \mathrm{~h} ; 2-\mathrm{pH} 4.5 ., 1$ week; 3-pH 7.5, 1 week; 4-pH 7.5, 1 week, dialyzed against water. Each spectrum results from 60000 transients obtained by using the $8 \mathrm{~K}$-frequency domain data point (spectral width $6,000 \mathrm{~Hz}$; recycle time $0.679 \mathrm{~s}$.; flip angle $30^{\circ}$ ). F-peaks coming from the ${ }^{13} \mathrm{C}$-enriched formaldehyde solution (formaldehyde monomer, 82.3 p.p.m.; methanol, 49.3 p.p.m.). P-peaks coming from the protein. $a, b, c, d, e, i, i^{1}:{ }^{13} \mathrm{C}$-formaldehyde - BSA links (see in the text).
At last, the two signals $i$ and $i^{\prime}$, around 50p.p.m., are very weak and badly resolved; their assignment needs further investigation.

Identical spectra have been obtained with other proteins (lyzozyme, $\beta$-lactoglobulin, ribonuclease).

\section{DISCUSSION}

From the above results and those of previous works, we are able to predict the ${ }^{13} \mathrm{C}$-n.m.r. chemical shifts of several formaldehyde-derived hydroxymethyl, methylene, methyl and formyl carbons which may occur during the reaction between formaldehyde and proteins (Table 2). 


\section{Tome et al.}

TABLE 2

${ }^{13} \mathrm{C}-n . m . r$, chemical shifts (TMS) of the formaldehyde derived formyl $(\mathrm{R}-\mathrm{CHO})$, hydroxymethyl $\left(\mathrm{R}-\mathrm{CH}{ }_{2} \mathrm{OH}\right)$, methyl $\left(\mathrm{R}-\mathrm{CH}_{3}\right)$ and methylene $\left(\mathrm{R}-\mathrm{CH}_{2}-\mathrm{R}^{\prime}\right)$ carbons with the amino acids side chains

\begin{tabular}{|c|c|c|c|c|}
\hline System & Formyl & Hydroxymethyl & Methylene & Methyl \\
\hline Lysine & 164.8 & 71.9 & - & $33.1-42.8^{\mathrm{d}}$ \\
\hline Serine $^{a}$ & - & 89.1 & - & - \\
\hline Histidine $^{a}$ & - & 71.7 & - & - \\
\hline Alanine $^{b}$ & - & 69.5 & - & - \\
\hline Tryptophane $\mathrm{a}^{\mathrm{a}}$ & - & 68.4 & - & - \\
\hline Cysteine & - & 65.7 & - & - \\
\hline Arginine & - & 65.2 & - & - \\
\hline Asparagine & - & 63.2 & - & - \\
\hline Glutanine & - & 63.2 & - & - \\
\hline Tyrosine & - & 60.0 & - & - \\
\hline Lys:Arg & - & - & 59.9 & - \\
\hline Lys:Cyst ${ }^{c}$ & - & - & $52.7-57.9^{d}$ & - \\
\hline Lys:Asn & - & - & 51.2 & - \\
\hline Lys:Gln & - & - & 51.2 & - \\
\hline Lys:Tyr & - & - & $47.1-55.3^{d}$ & - \\
\hline Cyst:Arg $\mathbf{c}$ & - & - & 43.8 & - \\
\hline Cyst:Gln ${ }^{c}$ & - & - & 41.4 & - \\
\hline Cyst:Asn ${ }^{\mathrm{c}}$ & - & - & 41.4 & - \\
\hline
\end{tabular}

${ }^{\text {a }}$ Ref. 7.

${ }^{b}$ Model for $N$-terminal, from ref. 8 .

${ }^{\mathrm{c}}$ Ref. 16.

$\mathrm{d}_{\text {Disubstituted on lysine nitrogen. }}$.

Hydroxymethyl carbons absorb in the frequency range $60-90$ p.p.m. and, with the exception of sulfhydryl, amide and phenol function, form according to an equilibrated reaction $(7,9,20,21)$. $N$-hydroxymethylation is the most prominent on lysine side chain but also occurs on $\alpha$-amino groups; no evidence for so-called Schiff-base formation was obtained $(8,22)$. Moreover, spontaneous methylation and formylation may proceed when lysine and formaldehyde are in excess, leading to $N$-methyllysine, $N-N^{\prime}$-dimethyllysine and $N$ formyllysine $(8,10,11)$. The formation of hydroxymethyls on amino groups (lysine and $N$-terminal) and of methyllysine, when BSA is treated by ${ }^{13} \mathrm{C}$-formaldehyde, is consistent with these observations. In addition, hydroxymethylations on histidine and amide groups which have also been suspected to act (23-25), are confirmed by the present results. On the other hand, hydroxymethylation on the phenol ring of tyrosine, which is unfavoured, probably will not occur.

The observed methylene bridges, formed between amino acids side chains, implicate lysine or cysteine which are able to link either together, or with arginine, asparagine or glutamine. In addition, lysine reacts with the phenol ring of tyrosine. Identification of some of these cross-linked systems brings support to hypotheses previously put forth $(4,12,14)$; however, the mechanism involved in their formation is not yet clearly understood. For instance, it seems surprising not to record lysine-lysine or cysteine-cysteine bridges. The ${ }^{13}$ C-n.m.r. chemical shifts of the methylene carbons in a variety of cross-linked systems are between 40 and 60 p.p.m. The experimental values are in agreement with those predicted for lysine-arginine and lysine-amide systems $(13,18)$, but somewhat at lower field for lysine-tyrosine (18). In addition, the de- 
shielding effect of the substitution of another methylene on the nitrogen of lysine side chain, in lysine-tyrosine and lysine-cysteine systems, is consistent with the effects previously reported for model systems of the same kind $(26,27)$.

The methylene bridge formed between lysine and arginine side chains, which was found to occur very easily in model mixtures, presumably represents the major crosslink in formaldehyde-BSA reaction. Although this bridge is acid labile, it is relatively stable. The n.m.r. study enables the visualization of such a bridge, previously proposed as well in model mixtures as in proteins $(12,13)$, but difficult to observe by other techniques.

The only acid resistant methylene bridge occurs between lysine and tyrosine. Its formation in model mixtures, probably through a Mannich reaction (28), is now definitely established; moreover a disubstitution on the nitrogen leads to the linkage of two tyrosine molecules on the lysine side chain. From our experiment using BSA, there is no evidence that this lysine-tyrosine bridge, often suspected to constitute most of the irreversibly bound formaldehyde on proteins (4), was formed. Actually it probably occurs at low concentration and its detection may be hindered because of the short spin lattice relaxation time (T1) of this methylene type (19).

The other bridges are more unstable. The favoured lysine-cysteine crosslink may occur (16) but rarely happens due to the lack of cysteine which is mostly in the cystine form in the studied proteins; however, formaldehyde may induce, in some cases, the reduction of cystine with liberation of reactive cysteine. The lysine-amide crosslink, previously postulated (12) could play a role in acidic medium and partially explains the observed gelification. Finally cysteine-arginine and cysteineamide bridges have also been observed in model mixtures (16), but are very unfavoured.

\section{CONCLUSION}

According to current studies, lysine possesses a highly reactive $\epsilon$-amino group allowing various covalent reactions with formaldehyde. Our ${ }^{13}$ C-n.m.r. experiments describe the structure of several hydroxymethyl, methyl and methylene derivatives which are linked to this amino group in model mixtures. The ${ }^{13} \mathrm{C}$ enriched formaldehyde treatment of proteins proved useful to point out the formation of methyllysine and a lysine-arginine crosslink as major products. However, further experiments are needed in order to identify definitively any of the components produced during the reaction between proteins and formaldehyde.

\section{REFERENCES}

1. Gustavson, K.H. (1956) The Chemistry of Tanning Processes. Academic Press, New York

2. Walker, J.F. (1964) Formaldehyde. Robert E. Krieger, Huntington, NY

3. Zelter, S.Z., Leroy, F. \& Tissier, J.F. (1970) Ann. Biol. Anim. Biochim Biophys. 10, 111 121

4. Bizzini, B. \& Raynaud, M. (1974) Biochimie 56, 297-303

5. Davis, P. \& Tabor, B.E. (1963) J. Polymer Sci. A1, 799-815

6. Tome, D., Bertrand, D., Viroben, G. \& DelortLaval, J. (1979) Ann. Technol. Agric. 28, 299318

7. Tome, D. \& Naulet, N. (1981) Int. J. Peptide Protein Res. 17, 501-507

8. Tome, D., Naulet, N. \& Martin, G.J. (1982) J. Chim Phys. 79, 361-366

9. Naulet, N., Tome, D. \& Martin, G.J. (1983) Org. Magn. Reson. 21, 564-566

10. Tyihak, E., Trezl, L. \& Rusnak, I. (1980) Pharmazie 35, 18-20

11. Trezl, L., Rusznak, I., Tyihak, E., Szarvas, T. \& Szende, B. (1983) Biochem. J. 214, 289-292

12. Fraenkel-Conrat, H. \& Olcott, H.S. (1948) J. Am. Chem. Soc. 70, 2673-2684

13. Taylor, S.K., Davidson, F. \& Ovenall, W. (1978) Photogr. Sci. Eng. 22, 134-138

14. Fraenkel-Conrat, H. \& Olcott, H.S. (1948) J. Biol. Chem. 174, 827-843

15. Koga, D., Imoto, T., Nakamura, Y., Fujikawa, S. \& Yagishita, K. (1978) Agric. Biol. Chem 42, $1147-1156$

16. Naulet, N. \& Tome, D. (1984) J. Chim. Phys. 81, $173-178$

17. Jentoft, J.E., Jentoft, N., Gerken, T.A. \& Dearborn, D.G. (1979) J. Biol Chem. 254, 4366-4370

18. Dewar, M.K., Johns, R.B., Kelly, D.P. \& Yates, J.F. (1975) Aust. J. Chem. 28, 917-924

19. Kelly, D.P., Dewar, M.K, Johns, R.B., Shao Wei-Let \& Yates, J.F. (1977) in Protein Cross- 
D. Tome et al.

linking, Biochemical and Molecular Aspects (Friedman, M., ed.), pp. 641-647, Plenum Press, New York

20. French, O. \& Edsall, J.T. (1945) Advan Protein Chem, 2, 277-355

21. Feraud, P.F. \& Le Henaff, Ph. (1968) Bull. Soc. Chim. 5, 1868-1978

22. Kitamoto, Y. \& Maeda, H. (1980) J. Biochem. 87, 1519-1530

23. Fraenkel-Conrat, H., Cooper, M. \& Olcott, H.S. (1945) J. Am Chem Soc 67, 950-954

24. Martin, C.J. \& Marini, M.A. (1967) J. Biol. Chem. 242, 5736-5743

25. Dunlop, P., Marini, M., Fales, H.M., Sokoloski, E. \& Martin, C.J. (1973) Bioorg. Chem 2, 235247
26. De Breet, A.J.J., Dankelman, W., Huysmans, W.G.B. \& De Wit, J. (1977) Angew. Makromol. Chem. 62, 7-31

27. Tomita, B. \& Hatono, S. (1978) J. Polymer Sci. 16, 2509-2525

28. Short, J. H. \& Ours, W. (1975) J. Heterocycl. Chem 12, 869-876

Address:

D. Tome

National Institute for Agricultural Research (INRA)

Laboratory of Animal Feed Technology

Rue de la Géraudiere

44072- Nantes Cedex

France 